\title{
PENGARUH KONSENTRASI NUTRISI AB MIX TERHADAP PERTUMBUHAN DAN HASIL SAWI PAKCOY (Brassica Rapa L.) DENGAN HIDROPONIK SISTEM SUMBU (WICK SYSTEM)
}

\author{
Made Suarsana1*, I Putu Parmila*, Kadek Agus Gunawan* \\ email: made.suarsana@unipas.ac.id \\ *Fakultas Pertanian Universitas Panji Sakti \\ Jl. Bisma, No 22, Singaraja, Bali, Indonesia 81116
}

\begin{abstract}
This study aims to determine the effect of the concentration of AB Mix nutrients on the growth and yield of pakcoy plants. This research has been carried out at the agronet house of the Faculty of Agriculture, Panji Sakti University at an altitude of $39 \mathrm{~m}$ above sea level (above sea level), in March-May 2019. The experimental design used a single randomized block design $(R C B D)$, namely the concentration of the $A B$ Mix nutrition treatment $(K)$. Statistical analysis showed that $A B$ Mix nutrient concentration had a very significant effect $(p<0.01)$ on plant height at 14 days after planting, 21 days after planting, 28 days after planting, total wet weight per plant, leaf area per plant, and economic fresh weight per plant. The nutrient concentration of $A B$ Mix $1.2 \%$ provides the best growth and yield of pakcoy plants. The higher concentration of AB Mix nutrition given causes the total wet weight per plant to change quadratically $\hat{Y}=-137.83 \times 2+$ $325.54 x-88.997$ with the coefficient of determination $(R 2)=1$ so that the optimum concentration $=1.18 \%$ and wet weight is obtained maximum total planting $=103,226$ grams .

Keywords: hydroponics, AB Mix nutrition, pakcoy
\end{abstract}

\begin{abstract}
Abstrak. Penelitian ini bertujuan untuk mengetahui pengaruh konsentrasi nutrisi AB Mix terhadap pertumbuhan dan hasil tanaman pakcoy. Penelitian ini telah dilaksanakan di rumah agronet Fakultas Pertanian Universitas Panji Sakti pada ketinggian tempat $39 \mathrm{~m}$ dpl (dari atas permukaan laut), pada bulan Maret -Mei 2019. Rancangan percobaan menggunakan rancangan acak kelompok (RAK) faktor tunggal yaitu perlakuan konsentrasi nutrisi AB Mix (K). Hasil analisis staistik menunjukkan konsentrasi nutrisi $\mathrm{AB}$ Mix berpengaruh sangat nyata $(\mathrm{p}<0,01)$ terhadap tinggi tanaman pada umur 14 hst, 21 hst, 28 hst, 35 hst, berat basah total per tanaman, luas daun per tanaman, dan berat segar ekonomis per tanaman. Konsentrasi nutrisi AB Mix 1,2\% memberikan pertumbuhan dan hasil tanaman pakcoy terbaik. Semakin tinggi konsentrasi nutrisi AB Mix yang diberikan menyebabkan berat basah total per tanaman berubah secara kuadratik yaitu $\hat{\mathrm{Y}}=$ $137,83 \times 2+325,54 \mathrm{x}-88,997$ dengan koefisien determinasi $(\mathrm{R} 2)=1$ sehingga diperoleh konsentrasi optimum $=1,18 \%$ dan berat basah total pertanaman maksimum $=103,226$ gram.
\end{abstract}

Kata kunci: hidroponik, nutrisi AB Mix, pakcoy

\section{PENDAHULUAN}

Tanaman memerlukan unsur hara untuk pertumbuhan dan perkembangannya. Ada 16 unsur yang merupakan unsur hara esensial yang dapat dibagi menjadi unsur hara makro dan mikro. Unsur hara makro relatif banyak diperlukan oleh tanaman seperti: $\mathrm{C}, \mathrm{H}, \mathrm{O}, \mathrm{N}, \mathrm{P}, \mathrm{K}$, $\mathrm{Ca}, \mathrm{Mg}, \mathrm{S}$, sedangkan unsur hara mikro juga sama pentingnya dengan unsur hara makro hanya dalam hal ini kebutuhan tanaman terhadap zatzat ini hanya sedikit seperti: Fe, Mn, Bo, Mo, Co, Zn dan Cl (Sutedjo, 1999)

Nutrisi AB Mix merupakan nutrisi yang digunakan untuk bertanam secara hidroponik Nutrisi AB Mix dibuat dalam dua kemasan yang berbeda yaitu Mix A dan Mix B, Mix A mengandung unsur Kalsium, sedangkan mix B mengandung sulfat dan fospat. 
Ketiganya tidak boleh dicampur dalam keadaan pekat agar tidak menimbulkan endapan, karena jika dicampur kation kalsium $(\mathrm{Ca})$ dalam Mix A bertemu dengan anion sulfat $\left(\mathrm{SO}_{4}{ }^{2-}\right)$ dalam Mix $\mathrm{B}$ akan terjadi endapan Kalsium Sulfat $\left(\mathrm{CaSO}_{4}\right)$ sehingga unsur $\mathrm{Ca}$ dan $\mathrm{S}$ tidak dapat diserap oleh akar dan apabila kation kalsium (Ca) dalam pekatan Mix A bertemu dengan anion fosfat $\left(\mathrm{PO}_{4}{ }^{3-}\right)$ dalam Mix B, maka akan terjadi endapan Kalsium fosfat $\left(\mathrm{Ca}_{3}\left(\mathrm{PO}_{4}\right)_{2}\right)$, sehingga unsur $\mathrm{Ca}$ dan $\mathrm{P}$ tidak dapat diserap oleh akar. Guna memenuhi kebutuhan hara atau nutrisi tersebut, tanaman hidroponik memerlukan larutan nutrisi atau pupuk (Sastro dan Nofi, 2016).

Pakcoy (Brassica rapa L.) adalah tanaman jenis sayuran yang termasuk keluarga Brassicaceae. Tumbuhan pakcoy masih memiliki kerabat dekat dengan sawi. Jadi pakcoy dan sawi merupakan satu genus, hanya varietasnya saja yang berbeda. Penampilannya sangat mirip dengan sawi, akan tetapi lebih pendek dan kompak, tangkai daunnya lebar dan kokoh, tulang daunnya mirip dengan sawi hijau, dan daunnya lebih tebal dari sawi hijau (Haryanto, 2006).

Hidroponik merupakan

metode bercocok tanam dengan memanfaatkan air tanpa menggunakan tanah dengan menekankan pada pemenuhan kebutuhan nutrisi bagi tanaman. Sistem hidroponik dapat memberikan suatu lingkungan pertumbuhan yang lebih terkontrol. Dengan pengembangan teknologi sistem hidroponik mampu mendaya gunakan air, nutrisi, pestisida secara nyata lebih efisien (minimalis system) dibandingkan dengan kultur tanah, terutama untuk tanaman berumur pendek seperti sayuran dan buah-buahan. Penggunaan sistem hidroponik tidak mengenal musim dan tidak memerlukan lahan yang luas dibandingkan dengan kultur tanah untuk menghasilkan satuan produktivitas yang sama (Kristi, 2018).

Hasil penelitian Wahyuni (2017) pengaruh konsentrasi nutrisi hidroponik DFT (Deep Flow Technique) terhadap pertumbuhan sawi. Penelitian ini menggunakan Rancangan Acak Kelompok (RAK) faktorial dengan faktor I adalah konsentrasi larutan nutrisi $\mathrm{AB}$ mix (N) yaitu, N1: 1,0\%, N2: 1,2\%, N3: $1,4 \%$ dan faktor II adalah macam varietas sawi (V) yaitu, V1: Pagoda, V2: Hijau, dan V3: Pakcoy. Varietas sawi hijau yang diberi konsentrasi nutrisi $\mathrm{AB}$ Mix 1,2\% memberikan hasil tertinggi dibandingkan dengan konsentrasi lainnya.

\section{BAHAN DAN METODE}

Percobaan ini dilaksanakan di rumah paranet Fakultas Pertanian Universitas Panji Sakti Singaraja, percobaan ini dimulai dari bulan Maret sampai dengan bulan Mei 2019. Bahan-bahan yang digunakan dalam percobaan ini adalah: Styrofoam ukuran panjang $50 \mathrm{~cm}$, lebar $35 \mathrm{~cm}$ dan tinggi $14 \mathrm{~cm}$, bambu, plastik UV, benih pakcoy, rokwool, gelas plastik, nutrisi $\mathrm{AB}$ Mix, dan kain flanel.

Alat-alat yang digunakan dalam percobaan ini adalah: aerator tipe LP 40, TDS meter, $\mathrm{pH}$ meter, gelas ukur, pinset, solder, pisau, gunting, lem tembak, hole saw, hand 
bor, timbangan, kamera dan alat tulis.

Percobaan ini menggunakan Rancangan Acak Kelompok (RAK) dengan faktor tunggal. Perlakuan yang di coba terdiri dari 3 konsentrasi nutrisi $\mathrm{AB}$ Mix (K) yaitu: $\mathrm{K} 1=$ konsentrasi nutrisi $\mathrm{AB}$ Mix $0,8 \%, \mathrm{~K} 2=$ konsentrasi nutrisi $\mathrm{AB}$ Mix 1,2\%, $\mathrm{K} 3=$ konsentrasi nutrisi $\mathrm{AB}$ Mix 1,6\%. Data hasil penelitian ini dianalisis secara statistika sesuai dengan rancangan yang digunakan, yaitu rancangan acak kelompok (RAK). Apabila antara perlakuan menujukan perbedaan yang nyata, dilanjutkan dengan uji BNT pada taraf $5 \%$. Untuk mengetahui hubungan antar variabel dilakukan analisis regresi (Hanafiah, 2001). Variabel yang diamati dalam penelitian ini adalah sebagai berikut: 1) tinggi tanaman (cm); 2) jumlah daun per tanaman (helai); 3) luas daun per tanaman (cm2); 4) berat basah tajuk per tanaman $(\mathrm{g}) ; 5)$ berat basah akar per tanaman $(\mathrm{g})$; 6) berat basah total per tanaman (g); 7) berat segar ekonomis per tanaman (g); 8)berat kering oven tajuk per tanaman $(\mathrm{g})$; 9) berat kering oven akar per tanaman $(\mathrm{g})$; 10) berat kering oven total per tanaman (g); 11) rasio daun-akar (g).

\section{HASIL DAN PEMBAHASAN}

Konsentrasi nutrisi AB Mix berpengaruh sangat nyata pada tinggi tanaman umur14 hst, 21 hst, 28 hst, 35 hst, dan berpengaruh tidak nyata pada umur 7 hst. Proses pertambahan tinggi tanaman pada umur 14 -35 hst, mempunyai respon yang tinggi dalam menyerap unsur hara. Pada umur 7 hst tanaman masih mengalami penyesuaian akibat pemindahan dari media penyemaian ke media tanam hidroponik sistem sumbu (wick system) (gambar 1).

Hasil penelitian menunjukkan bahwa perlakuan konsentrasi nutrisi AB Mix 1,2\% (K2) memberikan hasil tinggi tanaman tertinggi yaitu $29,07 \mathrm{~cm}$, hal ini berkaitan dengan pemberian konsentrasi nutris $\mathrm{AB}$ Mix yang tepat bagi tanaman pakcoy. Sutedjo (2010) menyatakan bahwa komposisi unsur hara makro maupun mikro sangat berpengaruh terhadap tanaman. Oleh karena itu dalam pemberian pupuk harus seimbang sesuai dengan kebutuhan tanaman.

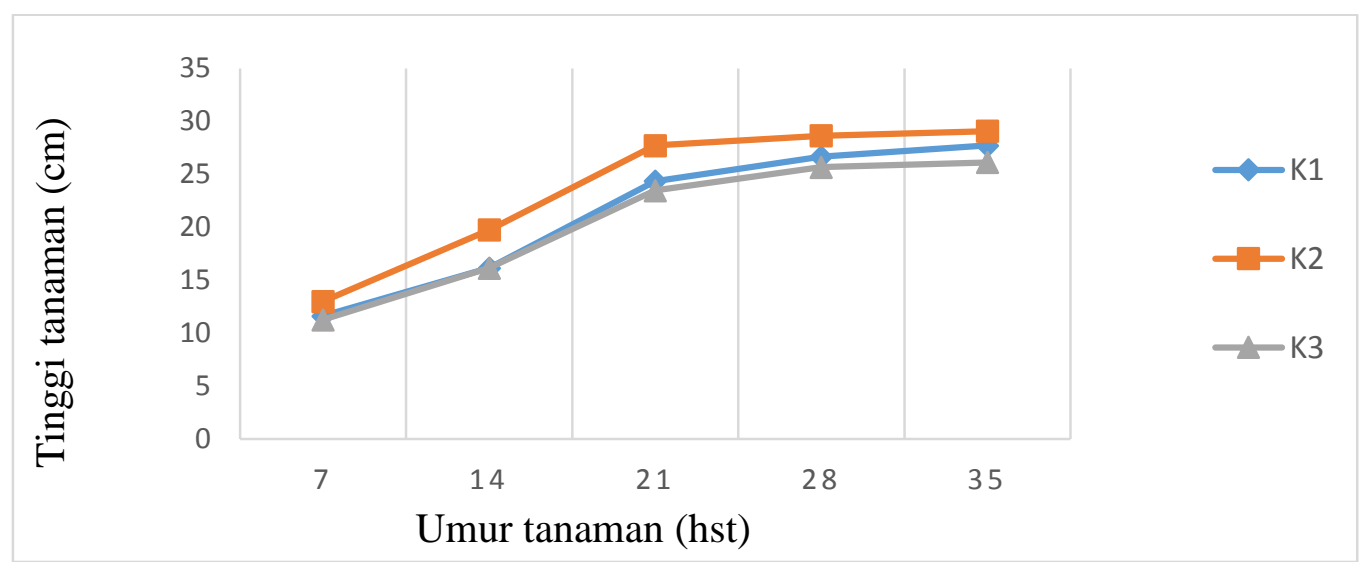

Gambar 1. Grafik pertumbuhan tinggi tanaman pada berbagai perlakuan konsentrasi nutrisi AB Mix. 
Pakcoy merupakan tanaman yang peka terhadap perubahan larutan nutrisi. Unsur hara makro yang sangat mempengaruhi larutan nutrisi hidroponik. Kekurangan unsur hara makro dapat menyebabkan penghambatan perkembangan akar di dalam sistem hidroponik sehingga mengganggu serapan nutrisi tanaman (Unlukara, 2008) sebagaimana ditunjukkan pada tabel 2 .

Tabel 1. Pengaruh konsentrasi nutrisi AB Mix terhadap berat basah akar per tanaman, berat kering oven akar per tanaman dan berat basah tajuk per tanaman

\begin{tabular}{cccccc}
\hline $\begin{array}{l}\text { Perlakuan } \begin{array}{l}\text { konsentrasi } \\
\text { nutrisi AB Mix }\end{array} \\
\text { Kerat basah } \\
\text { akar per-tanaman } \\
\text { (gram) }\end{array}$ & $\begin{array}{l}\text { Berat kering } \\
\text { oven akar per- } \\
\text { tanaman (gram) }\end{array}$ & $\begin{array}{l}\text { Berat basah } \\
\text { tajuk per-tanaman } \\
\text { (gram) }\end{array}$ \\
\hline $\mathrm{K}_{2}$ & 5,66 & $\mathrm{a}$ & 0,25 & 77,56 & $\mathrm{ab}$ \\
$\mathrm{K}_{3}$ & 7,61 & $\mathrm{~b}$ & 0,42 & 95,59 & $\mathrm{~b}$ \\
BNT 5\% & 7,10 & $\mathrm{a}$ & 0,38 & 71,91 & $\mathrm{a}$ \\
\end{tabular}

Keterangan : angka- angka dengan huruf yang sama pada perlakuan dan variabel yang sama menyatakan berbeda tidak nyata dengan uji BNT 5\%

Hasil penelitian menunjukkan bahwa perlakuan konsentrasi nutrisi $\mathrm{AB}$ Mix 1,2\% (K2), memberikan berat basah total per tanaman tertinggi yaitu 103,17 gram (Tabel 3). Hasil analisis regresi hubungan antara pengaruh konsentrasi nutrisi $\mathrm{AB}$ Mix (X) terhadap berat basah total per tanaman $(\hat{Y})$ menunjukan hubungan kuadratik dengan persamaan yaitu $\hat{Y}=-137,83 \times 2+325,54 x-88,997$ dengan koefisien determinasi $(\mathrm{R} 2)=$ 1 sehingga diperoleh Xopt $=1,18 \%$ dan $\hat{Y} \max =103,226$ gram (Gambar 4). Dari analisis regresi menunjukkan hubungan kuadratik, sehingga konsentrasi optimal pada konsentrasi nutrisi $\mathrm{AB}$ Mix $1,18 \%$ pada tanaman pakcoy. Hal ini disebabkan pemberian konsentrasi yang tepat dapat menyediakan unsur hara yang diperlukan untuk pertumbuhan tanaman pakcoy.

Untuk mendapatkan efisiensi pemberian nutrisi yang optimal, nutrisi harus diberikan dalam jumlah yang mencukupi kebutuhan tanaman. Bila tanaman diberikan nutrisi terlalu banyak dapat menyebabkan berkurangnya perkembangan vegetatif dan dapat menyebabkan keracunan bagi tanaman. Sebaliknya jika diberikan nutrisi terlalu sedikit dapat menyebabkan penghambatan perkembangan akar, sehingga mengganggu serapan nutrisi tanaman, meskipun tanaman tersebut tidak menunjukkan gejala defisiensi secara visual (Sutedjo, 2010). 
Tabel 2. Pengaruh konsentrasi nutrisi AB Mix terhadap berat kering oven tajuk per tanaman, berat basah total per tanaman, dan berat kering oven total per tanaman

\begin{tabular}{ccccc}
\hline $\begin{array}{l}\text { Perlakuan } \\
\text { konsentrasi } \\
\text { nutrisi AB Mix }\end{array}$ & $\begin{array}{l}\text { Berat kering } \\
\text { oven tajuk per- } \\
\text { tanaman (gram) }\end{array}$ & $\begin{array}{l}\text { Berat basah } \\
\text { total per- } \\
\text { tanaman (gram) }\end{array}$ & $\begin{array}{l}\text { Berat kering oven } \\
\text { total per-tanaman } \\
\text { (gram) }\end{array}$ \\
\hline $\mathrm{K}_{1}$ & 3,88 & 4,10 & $\mathrm{ab}$ & 83,22 \\
$\mathrm{~K}_{2}$ & 4,72 & 5,15 & $\mathrm{~b}$ & 103,17 \\
$\mathrm{~K}_{3}$ & 4,00 & 4,38 & $\mathrm{a}$ & 79,02 \\
BNT 5\% & $\mathrm{ns}$ & 3.36 & $\mathrm{~ns}$ \\
\hline
\end{tabular}

Keterangan : angka- angka dengan huruf yang sama pada perlakuan dan variabel yang sama menyatakan berbeda tidak nyata dengan uji BNT 5\%

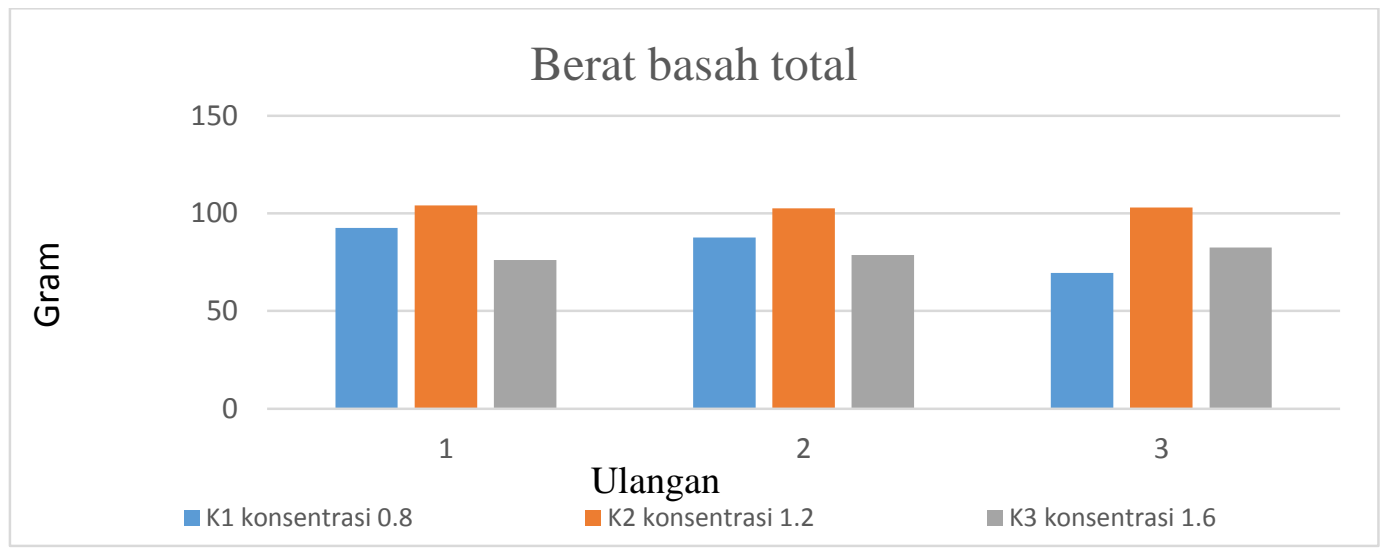

Gambar 2. Histogram pengaruh konsentrasi nutrisi AB Mix terhadap berat basah total per tanaman

Tabel 3. Pengaruh konsentrasi nutrisi AB Mix terhadap berat kering oven total per tanaman, berat segar ekonomis per tanaman dan rasio daun-akar

\begin{tabular}{cccccc}
\hline $\begin{array}{l}\text { Perlakuan } \\
\text { konsentrasi } \\
\text { nutrisi AB Mix }\end{array}$ & $\begin{array}{l}\text { Luas daun } \\
\text { per- tanaman } \\
\left(\mathrm{cm}^{2}\right)\end{array}$ & $\begin{array}{l}\text { Berat segar ekonomis } \\
\text { per- tanaman (gram) }\end{array}$ & $\begin{array}{l}\text { Rasio daun-akar } \\
\text { (gram) }\end{array}$ \\
\hline $\mathrm{K}_{1}$ & 19,89 & $\mathrm{a}$ & 133,70 & $\mathrm{a}$ & 43,80 \\
$\mathrm{~K}_{2}$ & 12,00 & $\mathrm{~b}$ & 225,97 & $\mathrm{~b}$ & 51,22 \\
$\mathrm{~K}_{3}$ & 10,86 & $\mathrm{a}$ & 175,37 & $\mathrm{ab}$ & 42,53 \\
BNT 5\% & 15.88 & & 65.22 & & $\mathrm{~ns}$ \\
\hline
\end{tabular}

Keterangan : angka- angka dengan huruf yang sama pada perlakuan dan variabel yang sama menyatakan berbeda tidak nyata dengan uji BNT 5\%.

Pada perlakuan konsentrasi nutrisi AB Mix 1,2\% (K2), memberikan berat segar ekonomis per tanaman tertinggi yaitu 225,97 gram (Tabel 4 dan gambar 3). Berpengarunya berat segar ekonomis per tanaman terkait dengan luas daun per tanaman yang berpengaruh sangat nyata $(\mathrm{p}<0,01)$ dengan luas daun terluas $51,22 \mathrm{~cm}^{2}$, pada perlakuan konsentrasi nutrisi AB Mix 1,2\% (K2) (Tabel 4). Hasil ini sesuai dengan pernyataan Poli 
(2009) dalam penelitiannya yang mengemukakan bahwa dengan meningkatnya luas daun tanaman maka akan secara otomatis meningkatkan berat segar tanaman. Karena daun merupakan organ yang mengandung air. Sehingga dengan luas daun yang semakin luas maka kadar air tanaman akan tinggi dan menyebabkan berat segar tanaman semakin tinggi.

Hasil penelitian Wahyuni (2017), pengaruh konsentrasi nutrisi hidroponik $(1 \%, 1,2 \%$ dan $1,4 \%)$ terhadap pertumbuhan beberapa varietas sawi (sawi pagoda, sawi hjau, dan pakcoy). Tanaman pakcoy atau sawi sendok memiliki berat segar terbesar dibandingkan dengan jenis sawi lainnya yang diuji, yaitu 154,78 gram per tanaman, pada konsentrasi nutrisi $1,4 \%$. Hal ini disebabkan tanaman Pakcoy memiliki tulang daun yang sukulen dan lebar sehingga memberi sumbangan yang besar terhadap berat segar per tanaman.

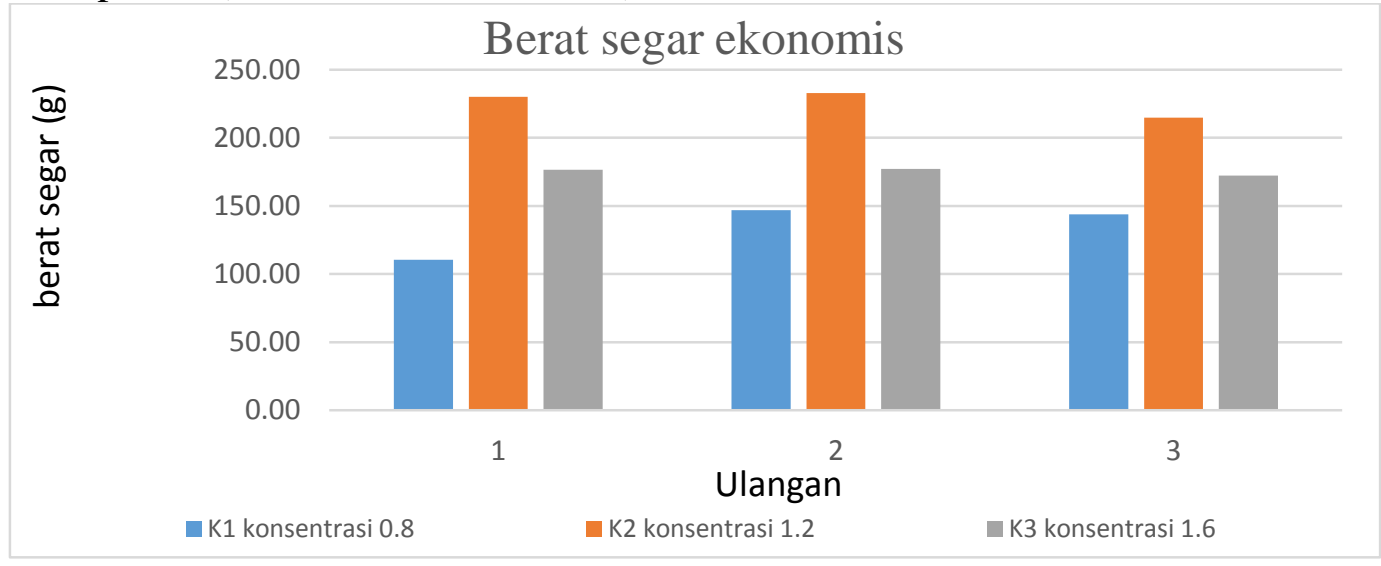

Gambar 3. Histogram pengaruh konsentrasi nutrisi AB Mix terhadap berat segar ekonomis

Hasil analisis data menunjukan bahwa perlakuan konsentrasi nutrisi AB Mix berpengaruh sangat nyata terhadap berat basah total per tanaman, namun bepengaruh tidak nyata terhadap berat kering oven total per tanaman pada tanaman pakcoy (tabel 3), hal ini disebabkan oleh tekanan turgor (Turgiditas) yaitu tekanan yang mendorong membran sel terhadap dinding sel pada tanaman. Tekanan ini menyebabkan timbulnya aliran osmosis air dari bagian dengan konsentrasi terlarut rendah (hipotonik) di luar sel ke dalam vakuola sel yang memiliki konsentrasi terlarut lebih tinggi (dwidjoseputro, 1994). 


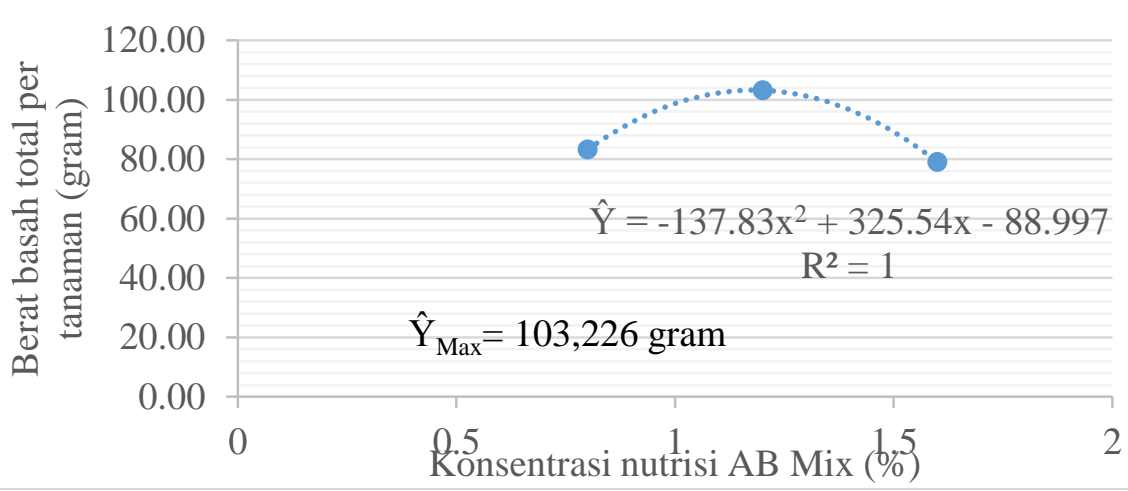

Gambar 4. Grafik hubungan pengaruh konsentrasi nutrisi AB Mix terhadap berat basah total per tanaman

\section{SIMPULAN}

1) Pengaruh perlakuan terhadap variabel yang diamati menunjukkan bahwa perlakuan konsentrasi nutrisi AB Mix berpengaruh sangat nyata $(\mathrm{p}<0,01)$ terhadap tinggi tanaman pada umur $14 \mathrm{hst}, 21$ hst, 28 hst, 35 hst, berat basah total per tanaman, luas daun per tanaman dan berat segar ekonomis per tanaman.

2) Konsentrasi nutrisi $\mathrm{AB}$ Mix $1,2 \%$ memberikan pertumbuhan dan hasil tanaman pakcoy terbaik.

3) Konsentrasi optimum pada nutrisi $\mathrm{AB}$ Mix yaitu 1,18\% dengan berat basah total pertanaman maksimum $=103,226$ gram.

\section{DAFTAR PUSTAKA}

Dwidjoseputro, D. 1994. Pengantar Fisiologi Tumbuhan. Jakarta: Gramendia

Elisa. 2018. Budidaya Hidroponik Yang Paling Meguntungkan. Jakarta: Garuda Pustaka

Furoidah, N. 2018. Efektivitas penggunaan $A B$ Mix terhadap pertumbuhan beberapa varietas sawi (brassica sp.), Seminar Nasional Dalam Rangka Dies Natalis UNS Ke 42. Prodi Agroteknologi, Fakultas Pertanian Universitas Islam Jember

Haryanto. 2006. Tenik budidaya sayuran pakcoy (sawi mangkok). Jakarta: penebar swadaya

Hanafiah, K. A. 2001. Rancangan Percobaan. Jakarta: Raja Grafindo Persada.

Istiqamah, A. Abdul, R. Aiyen. 2016. Respon Varietas Tanaman Sawi (Brassica Juncea L.) Terhadap Larutan Hara (Ab Mix) Pada Sistem Hidroponik. Agrotekbis. 4 (4): 374-383

Jones, J. B. 2005. Hydroponics: A Practicial Guide For the Soilless Grower. Florida: CRC Press

Kristi, A. A. 2018. Hidroponik rumahan. Yogyakarta: ANDI

Poli, M. G. M. 2009. Respon Produksi Tanaman Kangkung terhadap Variasi Waktu Pemberian Pupuk Kotoran Ayam. Soil Environment. 1 (7): 18-22 
Rukmana, R.2004. Bertanam Petsai dan Sawi. Yogyakarta: Kanisius

Sastro, Y. dan Nofi, A.R. 2016. Hidroponik Sayuran di Perkotaan. Jakarta: BPTP

Siswadi. 2008. Berbagai formulasi kebutuhan nutrisi pada sistem hidroponik.

Inovasi Pertanian. 7 (1):103110

Sutarya. 2005. Bertanam Sawi Pakchoy. Jakarta: Agro Media Pustaka

Sutedjo, M. M. 2010. Pupuk dan Cara Pemupukan. Jakarta: Rineka Cipta
Unlukara, A. B. Cemek, S. Karaman and Ersahin, S. 2008. Response of lettuce (Lactuca sativa var.crispa) to salinity of irrigation water. New Zealand Journal of Crop and Horticultural Science 36:265273

Wahyuni, E. S. 2017.Pengaruh Konsentrasi Nutrisi Hidroponik DFT Terhadap Pertumbuhan Sawi. Jurnal Bioshell. 6 (1): 333-339

Zulfitri. 2005. Analisis varietas dan polybag terhadap pertumbuhan serta hasil cabai (capsicum annum L.) Sistem hidroponik. Bulletin Penelitian 80:1-10 